\title{
Cannabidiol Interactions with Medications, Illicit Substances, and Alcohol: a Comprehensive Review
}

\author{
Premalatha Balachandran, $P h D^{7}$, Mahmoud Elsohly, PhD ${ }^{1,2}$, Kevin P. Hill, MD, MHS ${ }^{3,4}$ \\ 'National Center for Natural Products Research, Research Institute of Pharmaceutical Sciences, School of Pharmacy, University of Mississippi, \\ University, MS, USA; ${ }^{2}$ Department of Pharmaceutics and Drug Delivery, School of Pharmacy, University of Mississippi, University, MS, USA; \\ ${ }^{3}$ Department of Psychiatry, Harvard Medical School, Boston, MA, USA; ${ }^{4}$ Division of Addiction Psychiatry, Beth Israel Deaconess Medical Center, \\ Boston, MA, USA.
}

Cannabidiol, a non-intoxicating phytocannabinoid, has potential therapeutic effects over a broad range of disorders. Recently, there has been increased interest in CBD, as several studies showed promising anticonvulsant efficacy with few side effects. In 2018, a CBD-based oral solution, Epidiolex ${ }^{\circledR}$, was approved by the FDA to treat two severe forms of pediatric epilepsy, Dravet syndrome, and Lennox-Gastaut syndrome. Although only these two syndromes are recognized indications for CBD, it has been consumed in an unregulated fashion for a variety of indications including chronic pain, muscle stiffness, inflammation, anxiety, smoking cessation, and even cancer. While CBD legislation in the USA is confusing due to the differences in state and federal laws, CBD has proliferated in the US market in several forms such as CBD oil or capsules, hemp oil/extract, and also as an ingredient in several dietary supplements, syrups, teas, and creams. With the ever-increasing use of $\mathrm{CBD}$ and its widespread availability to the general public, it is important to examine and report on possible drug-drug interactions between CBD and other therapeutic agents as well as addictive substances such as alcohol and tobacco. A detailed literature search for CBD's possible interactions was conducted using online databases. As expected, CBD has been reported to interact with antiepileptic drugs, antidepressants, opioid analgesics, and THC, but surprisingly, it interacts with several other common medications, e.g. acetaminophen, and substances including alcohol. This review provides a comprehensive list of interacting drugs. The possible mechanisms for these drug-drug interactions are presented in table format. Given the growing popularity of $\mathrm{CBD}$ as a medication and the dearth of available information on CBD drug-drug interactions, it is critical to be aware of current drug-drug interactions and it will be important to investigate the impact of CBD upon concomitant medication use in future randomized, controlled trials.

KEY WORDS: cannabidiol; drug-drug interactions; cannabinoids; mechanism; cytochrome P450.

This manuscript has not been presented at a conference.

Received August 6, 2020

Accepted December 17, 2020

Published online January 29, 2021
J Gen Intern Med 36(7):2074-84

DOI: $10.1007 /$ s11606-020-06504-8

(C) Society of General Internal Medicine 2021

\section{INTRODUCTION}

The cannabis plant has been used to treat a variety of ailments for many centuries and includes multiple species, of which Cannabis indica and Cannabis sativa are best known ${ }^{1} . \Delta^{9}$ Tetrahydrocannabinol (THC) is the major psychoactive ingredient, and cannabidiol is a non-intoxicating ingredient. Cannabis sativa usually has a higher THC:CBD ratio than Cannabis indica. Thus, sativa strains often have more psychotropic effects whereas indica strains are more sedating ${ }^{2}$. As of July 2020, 33 states and the District of Columbia have medical cannabis laws and 11 states and the District of Columbia have recreational cannabis laws. Due to the recent change in cannabis laws, CBD consumer sales have skyrocketed; they are expected to increase from half a billion in 2018 to $\$ 1.8$ billion in $2022^{3}$. As CBD has gained more popularity and expanded unregulated use, its drug-drug interactions remain largely unknown. CBD is known to interact with cytochrome $\mathrm{P}_{450}$ drug metabolizing enzymes, and this affects co-administration of CBD with other pharmaceutical drugs that are also inhibited or metabolized by these enzymes ${ }^{4}$. The consequence of the lack of information on drug-drug interactions is an inadequate knowledge of their potential adverse reactions when consumed together. Interactions, either additive or synergistic, or contraindications are largely undescribed and are a major health concern. As evidenced from drug interaction databases such as the Medscape Drug Interaction Checker, which healthcare professionals and researchers primarily use to check for drug interactions, searches for CBD interactions typically yield few results. Therefore, a comprehensive detailed review is warranted to provide insight into this topic.

\section{METHODS}

We conducted a detailed online literature search of the databases Pubmed and Google Scholar (1975 to March 2020), along with the drug interaction databases Medscape Drug 
Interaction Checker and Drug Bank using the terms, cannabidiol (or CBD) with interactions $(n=19,943)$, narcotics $(n=4070)$; anti-depressants $(n=440)$; AED (1246); alcohol $(n$ $=1810)$; drug. In addition, CBD with specific drug names (acetaminophen ( $n=1776)$ and morphine (6034), for example) were also searched. The results regarding drug interactions from the search were extracted and summarized by 1 author (PB). This review's focus is not just limited to adverse effects but also any possible effects that could be attributable to CBD-drug interactions by simultaneous use either prescribed or consumed nonmedically. When examining CBD's interactions with nicotine, there were several references available on cannabis or marijuana as a whole plant with nicotine/ smoke, but none for CBD and nicotine/smoke. Cannabis/ marijuana plant-drug interactions are beyond the scope of this review.

\section{CANNABIDIOL'S MECHANISM OF ACTION}

CBD is a non-psychotomimetic phytocannabinoid that has broad range of possible therapeutic effects including anxiolytic, antidepressant, anticonvulsant, neuroprotective, antiinflammatory and immunomodulatory properties without any stimulant or convulsant properties ${ }^{5}$. CBD attenuates brain damage associated with neurogenerative or ischemic conditions. It affects synaptic plasticity and facilitates neurogenesis. The mechanism of these effects involves multiple pharmacological targets ${ }^{6}$. In animal models, CBD (a) blocks or reduces the spread of generalized seizures induced by maximal electroshock or $\gamma$-aminobutyric acid (GABA)-inhibiting drugs, (b) blocks simple partial seizures induced by the topical application of convulsant metals on the cortex, and (c) increases the seizure threshold for electrical kindling. CBD increased the potency of AEDs in animal models of partial and generalized motor seizures, but inhibited the action of AEDs in animal models of absence seizures ${ }^{7}$. CBD attenuated GABA release from ventral pallidum neurons, restoring the normal function of this system in psychotic patients ${ }^{8}$. CBD can also increase adult neurogenesis in mice, and this effect has been shown to be dependent on $\mathrm{CB} 1$ receptors 9 . $\mathrm{CBD}$ can act as a serotonin $1 \mathrm{~A}$ receptor $(5 \mathrm{HT} 1 \mathrm{~A})$ agonist. Aripiprazole, an atypical antipsychotic, acts as a partial agonist at this receptor, an effect that could, together with its actions on D2 and 5-HT2A receptors, contribute to the therapeutic effects of this drug.

\section{MECHANISMS BEHIND CANNABIDIOL'S INTERACTIONS WITH OTHER MEDICATIONS}

CBD is extensively metabolized by CYP450 enzymes in the liver, in particular by the isoforms CYP3A4 and CYP2C $19^{10}$. Furthermore, CBD is able to inhibit CYP2C19, CYP2D6, and CYP2C9, and may inhibit members of the CYP3 family ${ }^{11,12}$, leading to potential pharmacologic interactions with other drugs ${ }^{13,14}$. In animal models, repetitive administration of $\mathrm{CBD}$ may induce members of the CYP2B family ${ }^{4}$. Studies in mice have shown that CBD inactivates cytochrome P450 isozymes in the short-term, but can induce them after repeated administration. This is similar to their induction by phenobarbital, thereby strongly suggesting a role for the $2 b$ subfamily of isozymes of cytochrome P450. Another study showed this effect to be mediated by upregulation of mRNA for CYP3A, 2C, and 2B10 after repeated CBD administration ${ }^{15}$.

CBD is metabolized via the CYP3A4 enzyme, and approximately $60 \%$ of clinically prescribed medications are also metabolized through CYP3A4. In particular, drugs such as ketoconazole, itraconazole, ritonavir, and clarithromycin inhibit $\mathrm{CYP} 3 \mathrm{~A} 4{ }^{16}$ and this could lead to the increased levels of $\mathrm{CBD}$ when consumed together. CBD may increase serum concentrations of cyclosporine, sildenafil, antihistamines, haloperidol, antiretrovirals, and some statins (atorvastatin and simvastatin but not pravastatin or rosuvastatin) ${ }^{17}$. Interaction of these drugs with CYP3A4 leads to slower CBD degradation and can consequently lead to higher CBD levels that are pharmaceutically active for long periods of time. In contrast, phenobarbital, rifampicin, carbamazepine, and phenytoin induce CYP3A4, causing reduced CBD bioavailability.

GPR55 (G protein-coupled receptor 55) is highly expressed in large dorsal root ganglion neurons (added now) and, upon activation by agonists (e.g., THC), increases intracellular calcium in these neurons that may lead to neuronal excitability ${ }^{18}$. CBD is reported to function as GPR55 antagonist and suppresses GPR55's activities. The GPR55-dependent mechanism plays a major role in CBD's anti-psychotic and antiepileptic activities ${ }^{19}$. The therapeutic effects of CBD on inhibiting the neurotransmission in Dravet syndrome mouse model were mediated by its antagonism of GPR $55^{20}$.

CBD inhibition of the BCRP (Breast Cancer Resistance Protein) efflux function in the placental cotyledon warrants further research of co-administration of CBD with known BCRP substrates such as nitrofurantoin, cimetidine, and sulfasalazine ${ }^{21}$.

The Medscape Drug Interaction Checker database ${ }^{22}$ was searched for CBD's interactions with other drugs and the results are tabulated in Table 1.

$\mathrm{CB} 1$ receptors are located in the central nervous system and $\mathrm{CB} 2$ receptors are mostly found in the peripheral system ${ }^{23}$. Due to the lipophilic nature of CBD and THC, these compounds bind to these receptors and exert several pharmacological activities. CBD is a CB1 antagonist, a negative allosteric modulator at $\mathrm{CB} 2$, and an agonist at the transient receptor potential cation channel subfamily V member 1 (TRPV1) and serotonin 1A (5-HT1A) receptors, resulting in anxiolytic, antipsychotic, anticonvulsant, antioxidant, analgesic, and immunomodulatory functions, some of which buffer the harmful effects of THC like psychosis ${ }^{24}$. In particular, CB1, TRPV1, and 5HT1A are thought to be related to psychosis, anxiety, 
Table 1 Cannabidiol-Psychoactive Drug Interactions ${ }^{22}$

\begin{tabular}{|c|c|c|c|}
\hline Name of drug & Class of drug & Mechanism of interaction & $\begin{array}{l}\text { Clinical suggestions when co-administered with } \\
\text { CBD }\end{array}$ \\
\hline Carbamazepine & $\begin{array}{l}\text { Anti-epileptic } \\
\text { drug }\end{array}$ & $\begin{array}{l}\text { Will decrease the level or effect of cannabidiol by } \\
\text { affecting hepatic/intestinal enzyme CYP3A4 me- } \\
\text { tabolism. }\end{array}$ & $\begin{array}{l}\text { Consider an increase in cannabidiol dosage (based } \\
\text { on clinical response and tolerability) when co- } \\
\text { administered. }\end{array}$ \\
\hline Lamotrigine & $\begin{array}{l}\text { Anti-epileptic } \\
\text { drug }\end{array}$ & $\begin{array}{l}\text { CBD will increase the level or effect of lamotrigine } \\
\text { by inhibiting UGT2B } 7 \text { activity. }\end{array}$ & $\begin{array}{l}\text { Consider reducing the dose when concomitantly } \\
\text { using UGT2B7 substrates such as morphine, } \\
\text { losartan, diclofenac, tamoxifen, and ibuprofen. }\end{array}$ \\
\hline Oxcarbazepine & $\begin{array}{l}\text { Anti-epileptic } \\
\text { drug }\end{array}$ & $\begin{array}{l}\text { Will decrease the level or effect of CBD by } \\
\text { affecting hepatic/intestinal enzyme CYP3A4 me- } \\
\text { tabolism. }\end{array}$ & $\begin{array}{l}\text { Consider an increase in CBD dosage (based on } \\
\text { clinical response and tolerability) when co- } \\
\text { administered with a strong CYP3A4 inducer. }\end{array}$ \\
\hline Phenobarbital & $\begin{array}{l}\text { Anti-epileptic } \\
\text { drug }\end{array}$ & $\begin{array}{l}\text { Will decrease the level or effect of CBD by } \\
\text { affecting hepatic/intestinal enzyme CYP } 3 \text { A } 4 \text { me- } \\
\text { tabolism or CYP2C19 metabolism. } \\
\text { CBD discreetly potentiates the anticonvulsant effect } \\
\text { of phenobarbital. }\end{array}$ & $\begin{array}{l}\text { Consider an increase in CBD dosage (based on } \\
\text { clinical response and tolerability) when co- } \\
\text { administered with a strong CYP3A4 inducer. } \\
\text { Consider reducing the dose of sensitive CYP2C19 } \\
\text { substrates, as clinically appropriate, when co-ad- } \\
\text { ministered. }\end{array}$ \\
\hline Phenytoin & $\begin{array}{l}\text { Anti-epileptic } \\
\text { drug }\end{array}$ & $\begin{array}{l}\text { Will decrease the level or effect of CBD by } \\
\text { affecting hepatic/intestinal enzyme CYP3A4/ } \\
\text { CYP2C19 metabolism. } \\
\text { CBD may potentiate the anticonvulsant effects of } \\
\text { phenytoin. }\end{array}$ & $\begin{array}{l}\text { Consider an increase in CBD dosage (based on } \\
\text { clinical response and tolerability) when co- } \\
\text { administered with a strong CYP3A4 inducer. } \\
\text { Consider reducing the dose of sensitive CYP2C19 } \\
\text { substrates, as clinically appropriate, when } \\
\text { co-administered. }\end{array}$ \\
\hline $\begin{array}{l}\text { Chlordiazepoxide } \\
\text { Clonazepam } \\
\text { Ethosuximide }\end{array}$ & Benzodiazepine & $\begin{array}{l}\text { CBD reduces the anticonvulsant effects of these } \\
\text { drugs }\end{array}$ & $\begin{array}{l}\text { Consider an increase in the dose of these drugs } \\
\text { when co-administered. }\end{array}$ \\
\hline $\begin{array}{l}\text { Clobazam or } \\
\text { Diazepam }\end{array}$ & Benzodiazepine & $\begin{array}{l}\text { CBD will increase the level or effect of clobazam or } \\
\text { diazepam by affecting hepatic enzyme CYP2C19 } \\
\text { metabolism. CBD increases clobazam plasma } \\
\text { concentrations. }\end{array}$ & $\begin{array}{l}\text { Consider reducing the dose of sensitive CYP2C19 } \\
\text { substrates, as clinically appropriate, when co- } \\
\text { administered. }\end{array}$ \\
\hline Lorazepam & Benzodiazepine & $\begin{array}{l}\text { CBD will increase the level or effect of lorazepam } \\
\text { by decreasing its metabolism and potentially inhibit } \\
\text { UGT2B } 7 \text { activity. }\end{array}$ & $\begin{array}{l}\text { Consider reducing the dose when concomitantly } \\
\text { using UGT2B } 7 \text { substrates. }\end{array}$ \\
\hline Morphine & Opioid & CBD will increase the level or effect of morphine. & $\begin{array}{l}\text { CBD may potentially inhibit UGT2B } 7 \text { activity. } \\
\text { Consider reducing the dose when concomitantly } \\
\text { using UGT2B } 7 \text { substrates. }\end{array}$ \\
\hline Desipramine & $\begin{array}{l}\text { Tricyclic anti- } \\
\text { depressant }\end{array}$ & $\begin{array}{l}\text { Desipramine will increase the level or effect of } \\
\text { CBD by affecting hepatic/intestinal enzyme } \\
\text { CYP3A4 metabolism. }\end{array}$ & $\begin{array}{l}\text { Consider reducing the CBD dose when co- } \\
\text { administered with a moderate CYP3A4 inhibitor. }\end{array}$ \\
\hline Imipramine & $\begin{array}{l}\text { Tricyclic anti- } \\
\text { depressant }\end{array}$ & $\begin{array}{l}\text { CBD will increase the level or effect of imipramine } \\
\text { by affecting hepatic enzyme CYP2C19 metabolism. }\end{array}$ & $\begin{array}{l}\text { Consider reducing the dose of sensitive CYP2C19 } \\
\text { substrates, as clinically appropriate, when co- } \\
\text { administered. }\end{array}$ \\
\hline Trimipramine & $\begin{array}{l}\text { Tricyclic anti- } \\
\text { depressant }\end{array}$ & $\begin{array}{l}\text { CBD will increase the level or effect of } \\
\text { trimipramine by affecting hepatic enzyme } \\
\text { CYP2C19 metabolism. }\end{array}$ & $\begin{array}{l}\text { Consider reducing the dose of sensitive CYP2C19 } \\
\text { substrates, as clinically appropriate, when co- } \\
\text { administered. }\end{array}$ \\
\hline
\end{tabular}

and pain, respectively. As reported by several researchers, CBD appears to have minimal analgesic activity ${ }^{25}$. In addition, evidence supporting CBD's efficacy in treating psychiatric disorders remain scarce ${ }^{26}$.

CBD acts through several different targets and acts as cannabinoid receptor 1 and 2 antagonist (Fig. 1a), G-proteincoupled receptor 12 inverse agonist (Fig. 1a), glycine receptor subunit alpha-3 potentiator, 5-hydroxytryptamine receptor $1 \mathrm{~A}$ (Fig. 1a) and 2A agonist (Fig. 1b), 3A antagonist (Fig. 1c), prostaglandin $\mathrm{G} / \mathrm{H}$ synthase 1 and 2 inhibitor (Fig. 1d), and cytochrome P450 1B1 (Fig. 1e)/3A5 (Fig. 1e)/2D6 (Fig. 1f)/ 3A7 (Fig. 1f)/1A2 (Fig. 1g) inhibitor as well. The drugs that act on these targets as agonists, partial agonists, antagonists, negative modulators, inducers, binders, activators, blockers, and substrates could have the potential to interact as they work on the same target and mechanisms ${ }^{27}$. The possible drug-drug interactions of CBD based on these known targets against potential medications are collectively listed as flow chart figures that could have high clinical significance and relevance. The double-headed arrows indicate that the interactions are possible on either side.

However, the interactions presented in these figures are predicted from in vitro evidence, preclinical animal data or from their reported mechanism of actions, and their translation into clinical activities have not been established. These interactions could be concentration dependent and may require very high concentration of $\mathrm{CBD}$ and the other drug for any interaction to occur. Complexities in drug bioavailability, bioabsorption, pharmacokinetics in humans may also play a major role in CBD-drug interactions. Therefore, these reported interactions warrant further detailed research in human trials for accuracy and clinical significance.

\section{CANNABIDIOL INTERACTIONS}

CBD's interaction with AEDs and antidepressants is a topic of interest for physicians because of the possibility 
a

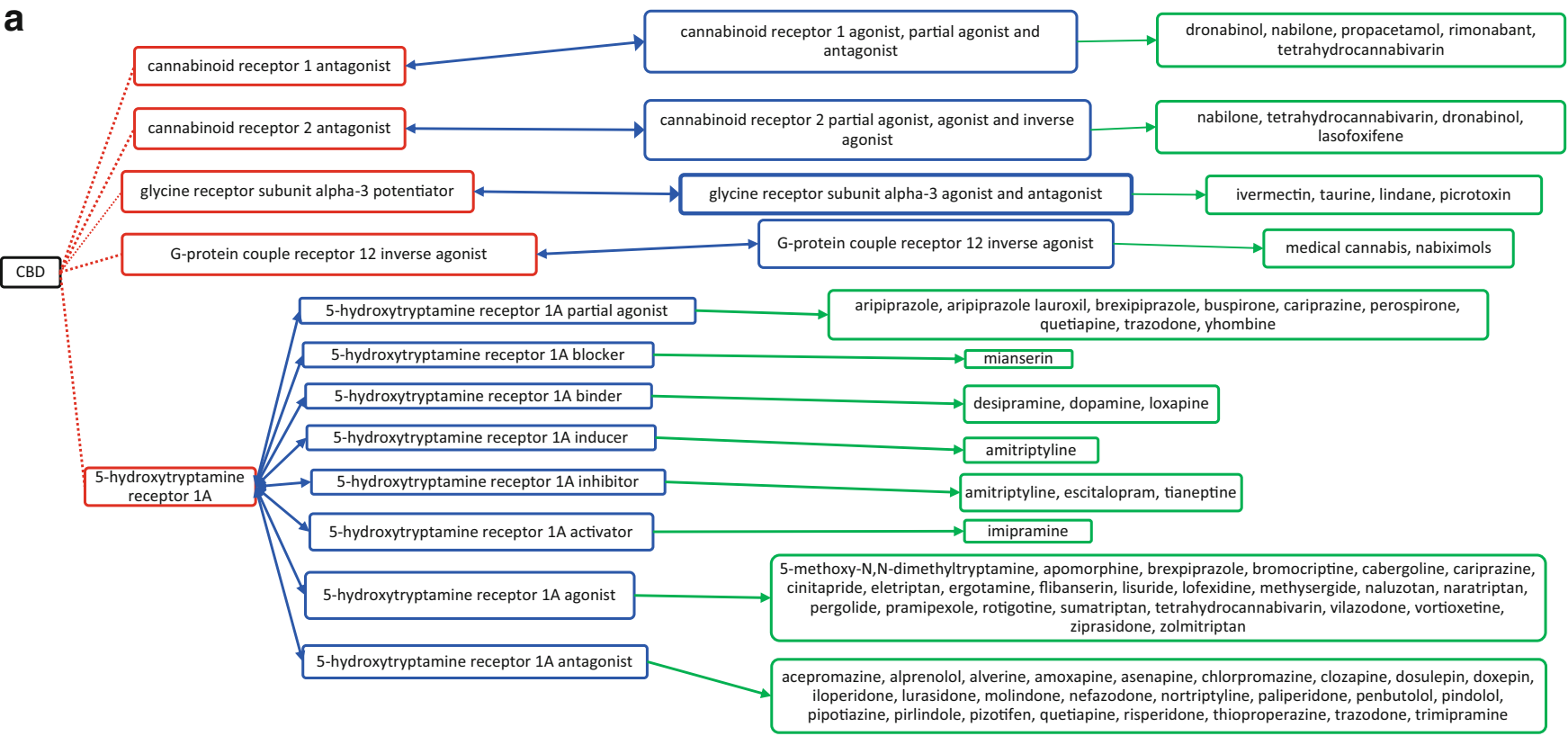

Figure 1 a Target-mediated drug-drug interactions of cannabidiol with cannabinoid and 5-hydroxytryptamine $1 \mathrm{~A}$ receptors ${ }^{27}$. b Targetmediated drug-drug interactions of cannabidiol with 5-hydroxytryptamine $2 \mathrm{~A}$ receptors ${ }^{27}$. $\mathrm{c}$ Target-mediated drug-drug interactions of cannabidiol with 5-hydroxytryptamine $3 \mathrm{~A}$ receptors ${ }^{27}$. d Target-mediated drug-drug interactions of cannabidiol with prostaglandin $\mathrm{G} / \mathrm{H}$ synthase 1 and 2 inhibitors ${ }^{27}$. e Target-mediated drug-drug interactions of cannabidiol with Cytochrome P450 1B1 and 3A5 inhibitor ${ }^{27}$. $\mathrm{f}$ Target-mediated drug-drug interactions of cannabidiol with Cytochrome P450 2D6 and 3A7 inhibitor ${ }^{27}$. g Target-mediated drug-drug interactions of cannabidiol with Cytochrome P450 1A2 inhibitor ${ }^{27}$. The red dotted lines indicate CBD's mechanism/actions as listed in red boxes. The blue double-headed arrows indicate the possible targets and interactions of CBD with other targets/mechanisms as listed in blue boxes. Green single-headed arrows indicate the drugs that act on these targets, as listed in green boxes. Such drugs may have additive/ synergistic or antagonistic effects if given concomitantly with CBD.>

of simultaneous consumption of both. CBD has been reported to interact with several anticonvulsants, including diazepam, lamotrigine, and phenytoin ${ }^{28,29}$; sedative drugs including barbiturates such as phenobarbital and hexobarbital $^{30}$; and narcotics such as codeine and morphine.

\section{Cannabidiol's Interaction with Anti-epileptic Drugs}

CBD has clear interactions with multiple AEDs, including clobazam, stiripentol, and valproate. CBD inhibits CYP2C19

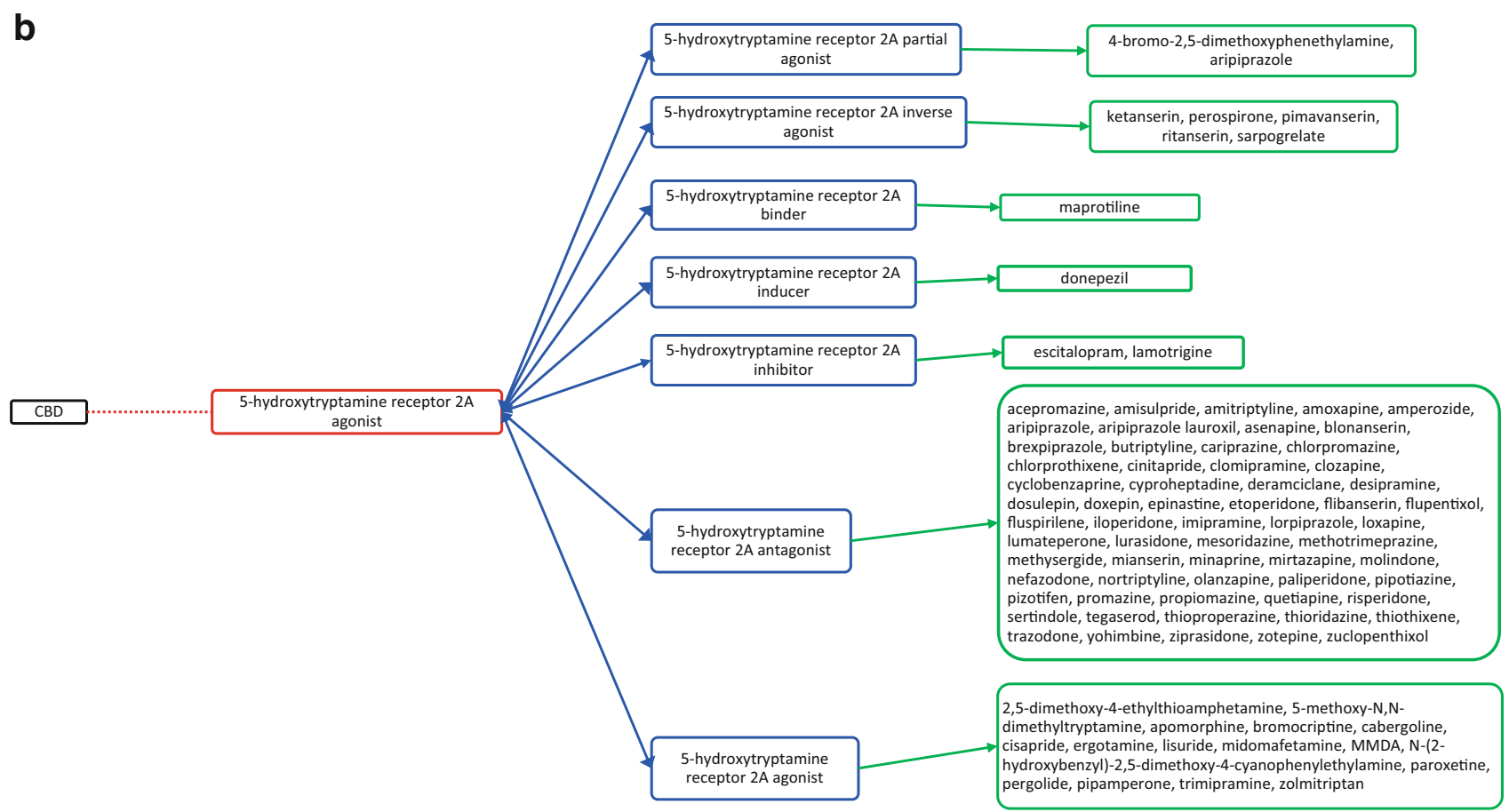

Fig. 1 continued. 


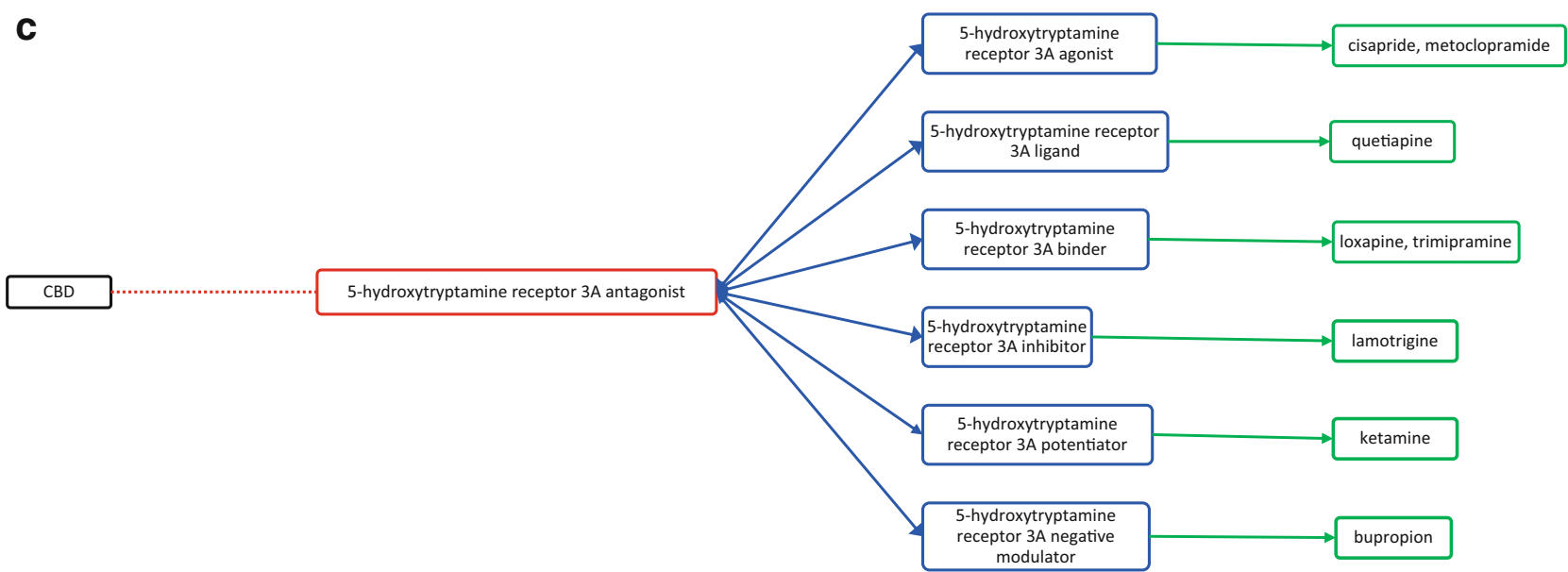

Fig. 1 continued.

and CYP3A4, which catalyze the metabolism of $\mathrm{N}$ desmethylclobazam ( $\mathrm{nCLB}$ ), an active metabolite of clobazam $^{11,31-33}$. The inhibition of these enzymes by CBD leads to the accumulation of nCLB, which is about 20-100\% as potent as clobazam ${ }^{34}$; therefore, monitoring of clobazam and nCLB levels is necessary when these medications are used concomitantly ${ }^{14}$. A highly purified CBD oral solution has been approved in the USA for seizures associated with LennoxGastaut and Dravet syndromes in patients aged $\geq 2$ years, for which AEDs are commonly used. A recent trial investigated the impact of CBD on steady-state pharmacokinetics of clobazam (and nCLB), stiripentol, and valproate ${ }^{35}$. The study also examined the reciprocal effect of these drugs on CBD's safety and tolerability and its major metabolites (7-hydroxy-cannabidiol [7-OH-CBD] and 7-carboxy-cannabidiol [7-COOH-CBD]) when co-administered. Concomitant $\mathrm{CBD}$ had significant effect on nCLB exposure (with 3.4-fold $\mathrm{C}_{\max }$ (maximum concentration) and AUC (area under the concentration-time curve)), and little effect on clobazam or stiripentol exposure, while no clinically relevant effect on valproate exposure was observed. Stiripentol decreased 7-OH-CBD exposure by $29 \%$ and $7-$ $\mathrm{COOH}-\mathrm{CBD}$ exposure by $13 \%$. CBD was moderately welltolerated when co-administered with $\mathrm{AEDs}^{35}$. The most common side effects of CBD are diarrhea and sedation ${ }^{36}$. There was also an increased incidence of aspartate aminotransferase and

d

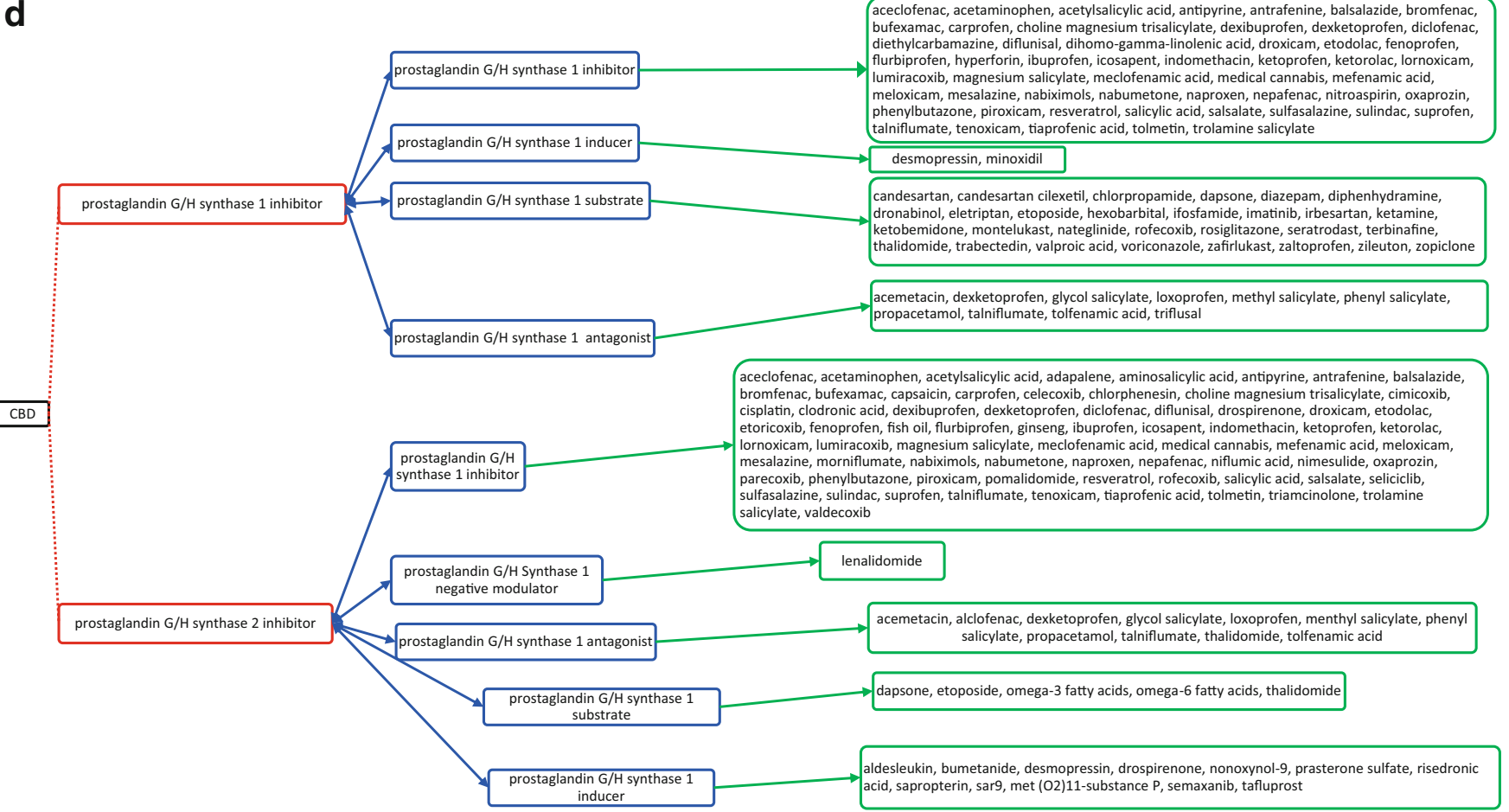

Fig. 1 continued. 


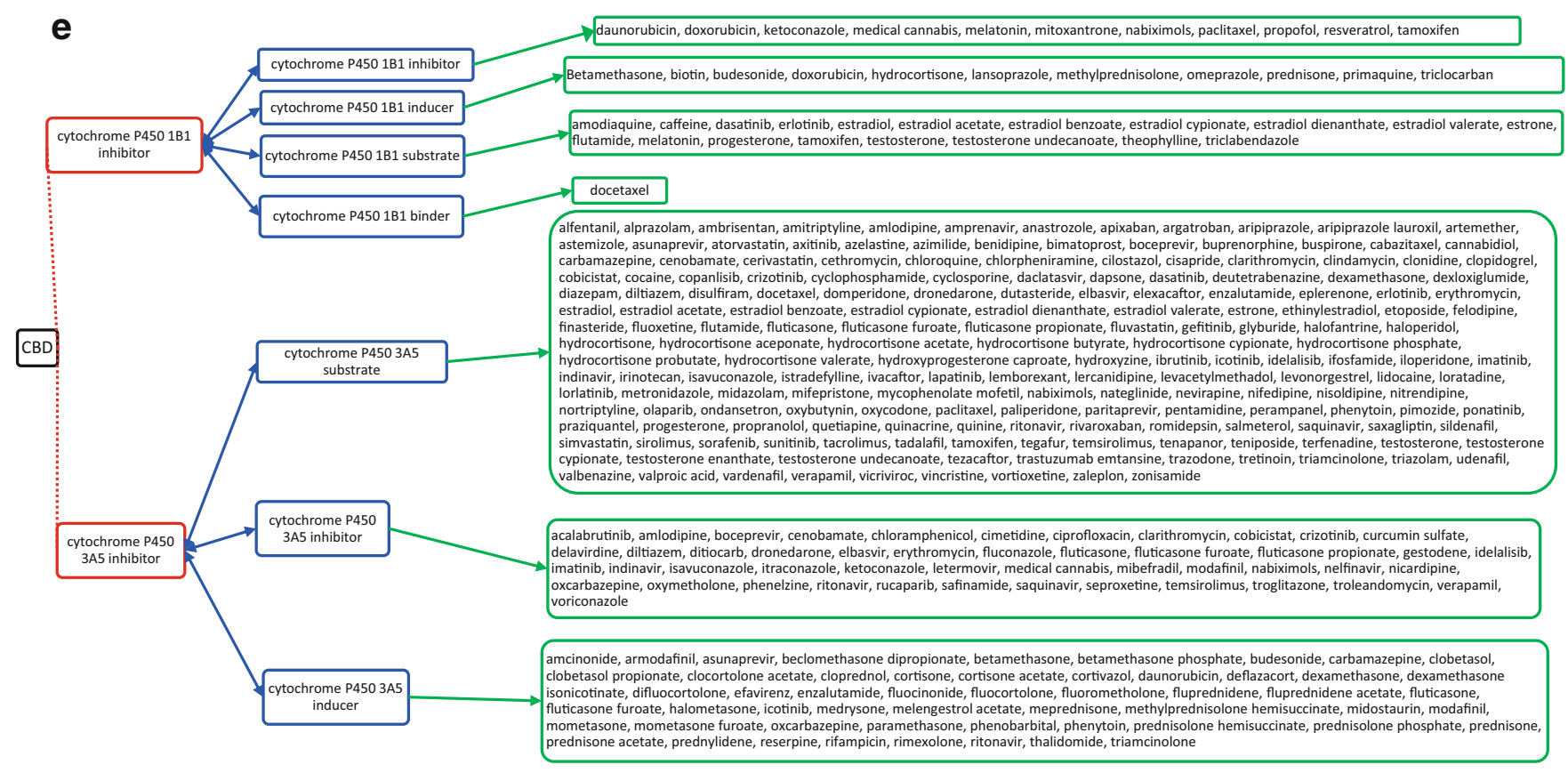

Fig. 1 continued.

alanine aminotransferase elevations while taking $\mathrm{CBD}$, with concomitant valproate ${ }^{37}$.

A pharmacodynamic animal study using maximal electroshock and audiogenic seizure models showed that CBD potentiated the anticonvulsant effects of phenytoin by twofold and discreetly potentiated the effect of phenobarbital. CBD also reduced the anticonvulsant properties of chlordiazepoxide, clonazepam, and ethosuximide ${ }^{29,38,39}$. A pharmacokinetic interaction between CBD and clobazam was reported with decreased clobazam serum levels noted after increasing CBD doses ${ }^{40}$. Another study suggests that CBD is effective in reducing seizure frequency and severity from baseline in

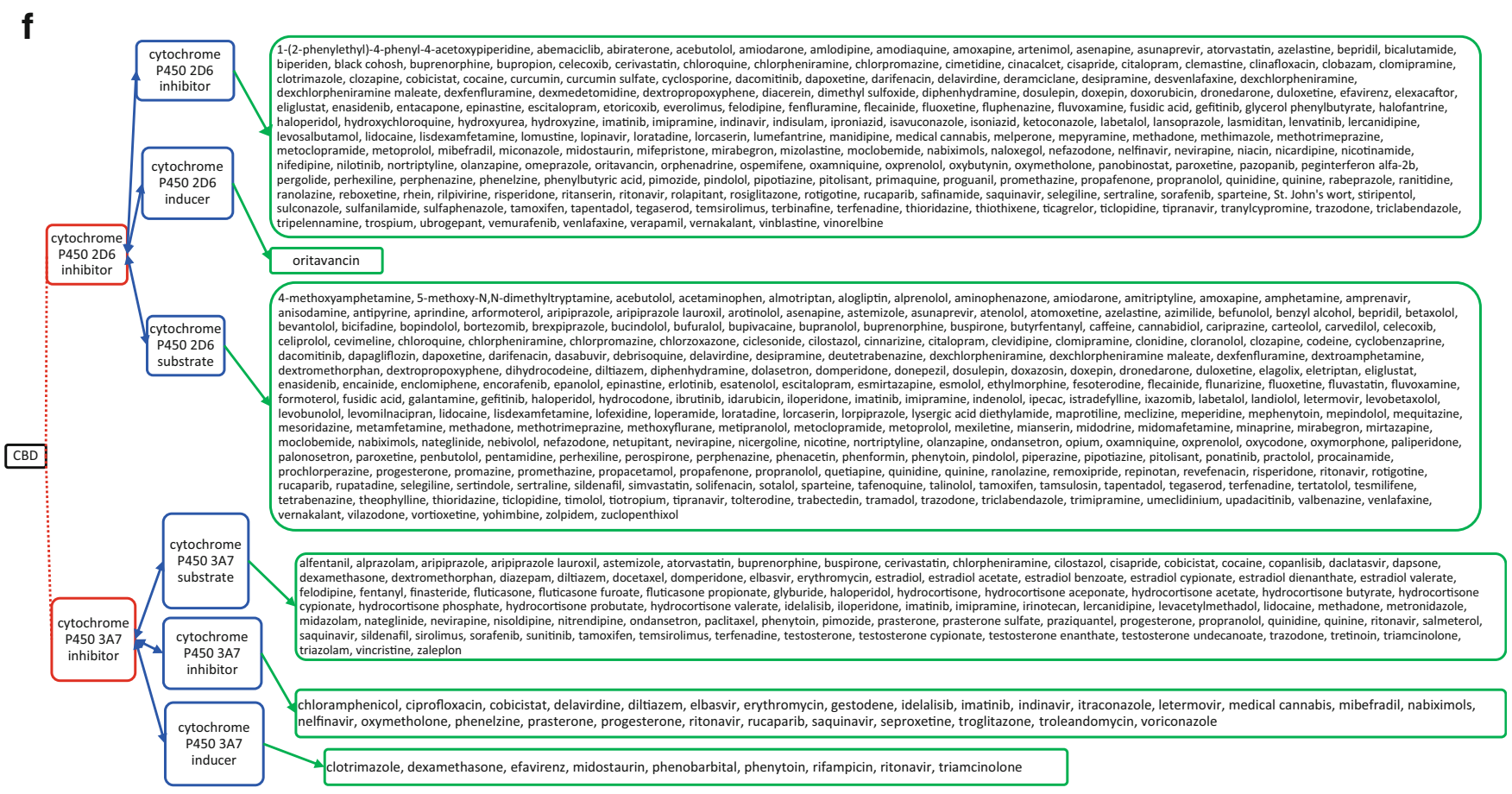

Fig. 1 continued. 


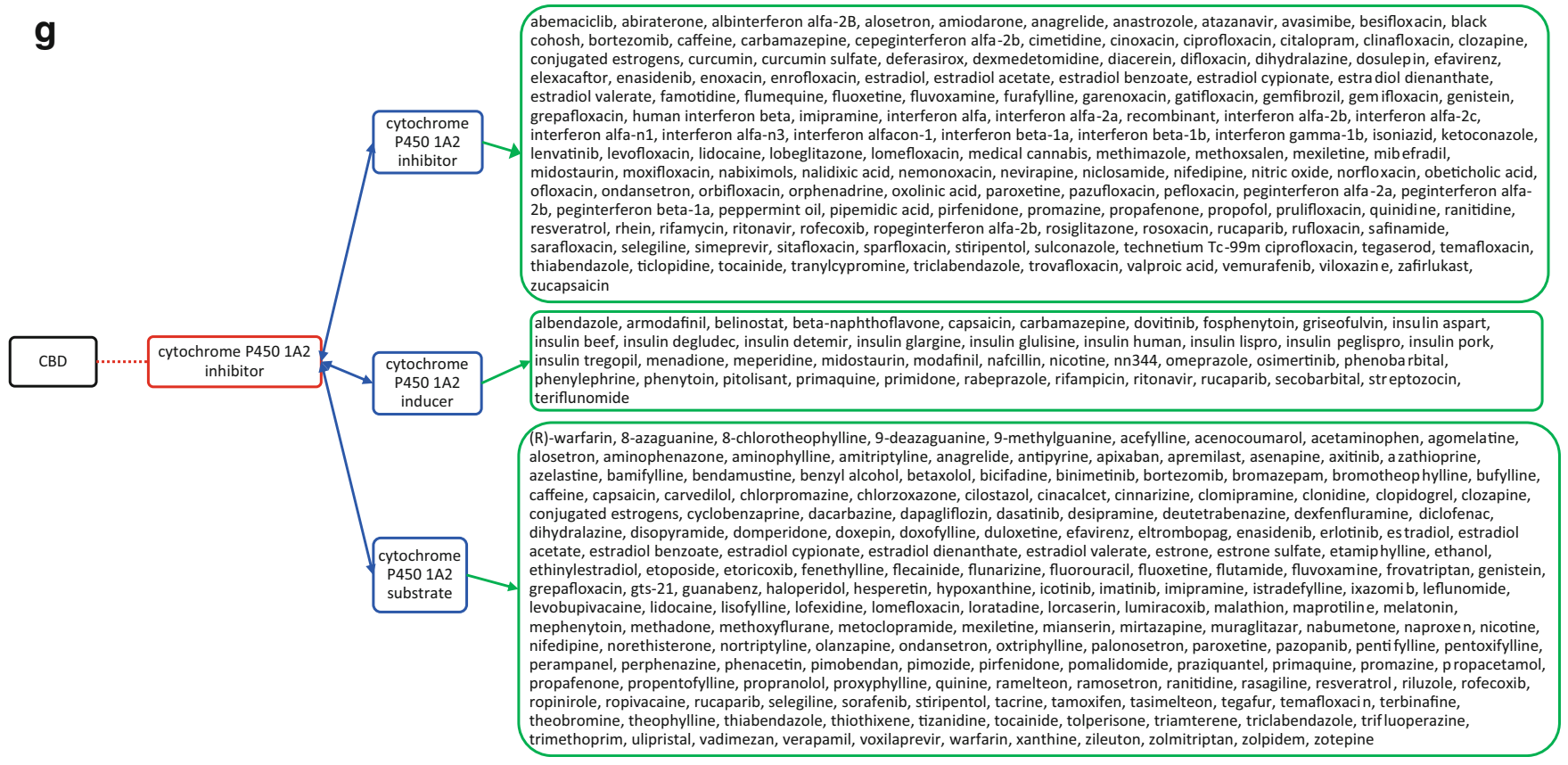

Fig. 1 continued.

adults and children with treatment-resistant epilepsy. According to this study, CBD has its own seizure-reducing efficacy and not affected by pharmacokinetic drug-drug interactions with other AEDs. The efficacy of AEDs can be modulated by CBD but CBD's anti-epileptic efficacy is unaffected by $\mathrm{AEDs}^{41}$.

Socala et al. ${ }^{42}$ observed that CBD increased the activity of topiramate, oxcarbazepine, pregabalin, tiagabine, and gabapentin, but did not affect the anticonvulsant effect of lamotrigine and lacosamide. Increased anticonvulsant activity of AEDs was partly related to pharmacokinetic interactions with CBD because CBD increased serum and brain concentrations of these AEDs. Although CBD did not affect the anticonvulsant activity of lacosamide, pharmacokinetic interactions between these two drugs cannot be excluded as CBD increased the brain concentration of lacosamide and vice versa. Interestingly, cannabidiol attenuated the anticonvulsant activity of levetiracetam and this interaction is pharmacodynamic in nature because no changes in serum and brain concentrations of either levetiracetam or CBD were observed.

\section{Cannabidiol's Interaction with Antidepressants}

CBD inhibits hepatic enzyme CYP2D6, and because of this inhibition, the serum concentrations of selective serotonin reuptake inhibitor (SSRIs), tricyclic antidepressants, antipsychotics, beta-blockers, and opioids may be increased as these antidepressants are metabolized by this enzyme. CBD can also affect metabolism of omeprazole and risperidone by CYP2D6 interactions $^{43}$. CBD also interacts with monoamine oxidase inhibitors (MAOIs) like tranylcypromine, phenelzine, and isocarboxazid by inhibiting their metabolism and causing these substances to remain in the circulatory system for longer periods of time leading to unpleasant side effects ${ }^{44}$.

When sertraline, a SSRI, was administered in combination with CBD in mouse model of post-traumatic stress disorder, the combination produced synergistic action on cognitive and emotional disturbances (severe anxiety and aggressive behavior ${ }^{45}$. The noradrenergic antidepressant, desipramine, when administered concurrently with CBD, at subtherapeutic doses of both, resulted in significant antidepressant like effects, thus implicating a synergistic or additive mechanism ${ }^{46}$.

Amitriptyline, a tricyclic antidepressant, is metabolized by cytochrome P450 isozymes CYP2D6, CYP2C19, CYP3A4, CYP1A2 and CYP2C9, and CBD inhibits these enzymes, which may increase adverse effects simultaneously (e.g., anticholinergic syndrome, drowsiness, and QT interval prolongation) $)^{47}$.

Additionally, gabapentin, pregabalin, citalopram, paroxetine, and mirtazapine are all metabolized by cytochrome enzymes that are known to be inhibited by CBD and coadministration of CBD with these medications may have adverse effects ${ }^{47}$.

\section{Cannabidiol's Interaction with Opioids}

CBD has been shown to have divergent effects when coadministered with opioids. CBD's interaction with morphine varied in different behavior models. For example, when the acetic acid stimulated stretching assay model was used, the combination showed synergistic effects. In the hot plate thermal nociceptive assay model, acetic acid decreased operant 
responding for palatable food model and sub-additive effects (an effect that is less than additive) were observed. These results suggest that distinct mechanisms of action underlie the interactions between CBD and morphine. Thus, the choice of appropriate combination therapies for the treatment of acute pain conditions may depend on the underlying pain type and stimulus modality ${ }^{48}$.

CBD is shown to inhibit heroin (diamorphine) metabolism and 6-monoacetylmorphine hydrolysis in in vitro conditions, which may be of clinical relevance ${ }^{49}$. A double-blind, placebo-controlled, crossover study in healthy volunteers with concomitant use of CBD and fentanyl showed that CBD does not exacerbate adverse effects associated with fentanyl and coadministration was well tolerated ${ }^{50}$.

\section{Cannabidiol's Interactions with $-\Delta^{9}$ - Tetrahydrocannabinol (THC)}

There are 565 chemical compounds and 120 phytocannabinoids (as of 2017) isolated from cannabis, including THC and $\mathrm{CBD}^{51}$. THC produces the main psychoactive effects of cannabis, while CBD does not appear to have similar effects. Studies conflict as to whether CBD attenuates or exacerbates the behavioral and cognitive effects of THC. This includes the effects of CBD on THC-induced anxiety ${ }^{52}$, psychosis $^{53}$, and cognitive deficits ${ }^{54}$. In a mouse model of paclitaxel-induced neuropathic pain, CBD synergized the effects of THC in attenuating mechanical allodynia, pain from usually non-painful stimuli. Also, CBD attenuated oxaliplatin- but not vincristine-induced mechanical sensitivity ${ }^{55}$. CBD inhibited the acute effects of THC and decreased THC effects on brain regions involved in memory, anxiety, and body temperature regulation ${ }^{56}$.

On the basis of CBD:THC ratios in cannabis, individuals from different populations were directly compared on indices of the reinforcing effects of drugs, explicit liking, and implicit attentional bias to drug stimuli. When intoxicated, smokers of high CBD:THC strains showed reduced attentional bias to drug and food stimuli compared with smokers of low CBD:THC. Those smoking higher CBD:THC strains also showed lower self-rated liking of cannabis stimuli on both test days. These reports suggest that CBD has potential as a treatment for cannabis use disorder ${ }^{57}$.

As both THC and CBD are hepatically metabolized, the potential exists for pharmacokinetic drug interactions via inhibition or induction of enzymes or transporters. In a study on the co-administration of CBD with THC in 5:1 dose ratio, CBD did not alter the trajectory of enduring THC-induced anxiety nor tolerance to the pharmacological effects of THC. There was no evidence of CBD potentiation of the behavioral effects of THC whereas CBD:THC in 1:1 co-administration increased histone 3 acetylation $(\mathrm{H} 3 \mathrm{~K} 9 / 14 \mathrm{ac})$ in the VTA (ventral tegmental area are group of neurons in the midbrain) and $\Delta \mathrm{FosB}$, a transcription factor expression in the nucleus accumbens. Increased histone 3 acetylation in the VTA region associated with addictive properties of drug abuse. These changes suggest that $\mathrm{CBD}$ might have some protective effects over THC's adverse effects over these brain regions and the process of memory ${ }^{58}$.

\section{Cannabidiol's Interaction with Other Drugs}

Pharmacodynamic interactions may occur if CBD is administered with other central nervous system depressant drugs and cardiac toxicity may occur via additive hypertension and tachycardia with sympathomimetic agents. More vulnerable populations, such as older patients, may benefit from the potential symptomatic and palliative benefits of cannabinoids but are at increased risk of adverse effects ${ }^{59}$.

Warfarin. A case study described a patient with CBD treatment for the management of epilepsy, ultimately necessitating a $30 \%$ reduction in warfarin dose to maintain therapeutic international normalized ratio (INR) values ${ }^{60,37}$ with excessive bleeding as side effects.

Cyclosporine and Tacrolimus. CBD has the potential to affect the immunosuppressant cyclosporine's metabolism which may result in increased cyclosporine blood levels and an increase in its toxic side effects. Another study reported CBD's interaction with the immunosuppressant tacrolimus with 3 -fold increase in dose-normalized tacrolimus concentrations ${ }^{61}$.

Acetaminophen. Caution should be taken when CBD is used with medications with the potential to cause hepatic injury, such as acetaminophen. CBD carries a recommendation for lowered doses in patients with hepatic impairment ${ }^{62}$. In a recent animal study, co-administration of CBD at the dose of $116 \mathrm{mg} / \mathrm{kg}$ (human dose of CBD is $10 \mathrm{mg} / \mathrm{kg}$ ) with acetaminophen $(400 \mathrm{mg} / \mathrm{kg})$ resulted in $37.5 \%$ mortality associated with liver injury. No mortality was observed in the CBDalone or acetaminophen-alone groups. The co-administration led to greater activation of c-Jun N-terminal kinase (JNK). Surprisingly, these effects were not observed in mice with a higher dose of CBD (290 mg/kg CBD with mouse equivalent dose of $25 \mathrm{mg} / \mathrm{kg}$ ). This shows an interesting paradoxical effect of CBD/APAP-induced hepatotoxicity ${ }^{63}$.

Capsazepine. Co-administration of $\mathrm{CBD}$, together with a TRPV-1 antagonist, capsazepine, reduces L-DOPA-induced dyskinesia (LID) by acting on $\mathrm{CB} 1$ and PPAR $\gamma$ receptors and reducing the expression of the inflammatory markers cyclooxygenase- 2 and nuclear factor-kappa $\mathrm{B}^{64}$. These interactions could play a significant role as L-DOPA remains the most effective pharmacotherapy for Parkinson's disease.

Other reports also demonstrate the possible interactions of CBD with rufinamide, zonisamide, and eslicarbazepine - increased accumulation of these drugs in the blood with concomitant use of $\mathrm{CBD}$ and their levels should be closely monitored ${ }^{37}$.

In a recent publication, Wilson-Morkeh et al. ${ }^{47}$ listed the interactions of CBD with corticosteroids (CS), commonly used 
drugs in the field of rheumatology. Hydrocortisone and prednisolone, commonly used CS, are both metabolized by the cytochrome P450 enzyme CYP3A ${ }^{65}$. CBD, as potent inhibitor of CYP3A when with these steroids may decrease glucocorticoid clearance and increase risk of systemic CS-induced side effects as well ${ }^{66}$. In addition, CBD could potentially interact with naproxen, tramadol, celecoxib, etoricoxib, fluoxetine, and tofacitinib as these are metabolized in the liver by cytochrome P450 enzymes. Another widely used RA drug, baricitinib, could be an exception as it was cleared by kidneys with minimal mediation by CYP3A4, and thus, the CBD interaction could be minimal. Methotrexate (MTX), hydroxychloroquine (HCQ), sulfasalazine (SSZ), mycophenolate mofetil (MMF), mesalazine, adalimumab, etanercept, abatacept, infliximab, and rituximab belong to the class of DMARDs ("disease-modifying anti-rheumatic drugs"), and these drugs have not been shown to produce interactions with $\mathrm{CBD}^{47}$.

\section{Cannabidiol's Interactions with Alcohol}

Although CBD's effects on alcohol consumption are poorly understood, CBD is known to act as an agonist of the 5-HT1A receptors and results suggest that $\mathrm{CBD}$ can attenuate alcohol consumption and potentially protect against certain harmful effects of alcohol, such as liver and brain damage ${ }^{67}$. When CBD was injected $30 \mathrm{~min}$ prior to each alcohol binge episode, it protected against hepatic injury, as measured by an attenuation in multiple markers of liver injury and oxidative stress ${ }^{68}$. Similarly, when CBD was co-administered with ethanol to rats, CBD was able to attenuate alcohol-induced brain damage in the hippocampal and entorhinal cortices. Alcohol-induced cell death was reduced by approximately $60 \%$ in both hippocampal granular cells and the entorhinal cortical pyramidal cells $^{69}$. In a clinical study, CBD, when consumed with alcohol, produced significant impairments of motor and psychomotor performances, overestimations of time production (estimation of alcohol content over various time periods) and subjective responses indicating some protective effects, including an accurate self-perception of one's intoxication and deficits. CBD did not prevent enhanced locomotor response once alcohol sensitization had developed ${ }^{70}$. CBD also lowered blood alcohol levels ${ }^{71}$. The timing and dosage of CBD administration could influence alcohol pharmacokinetics. Long-term effects of CBD on alcohol-induced anxiety and impulsivity need further exploration ${ }^{67}$.

\section{CONCLUSION}

This review provides an insight into the possible and potential interactions of CBD with other classes of commonly used drugs based on the evidence and knowledge currently available. Despite the increased popularity of CBD as a medication for myriad medical conditions, the limited availability of applicable pharmacokinetic and pharmacodynamic information highlights the need to initiate prescribing CBD using a "start low and go slow" approach, carefully observing the patient for desired and adverse effects. Further clinical studies in the patient populations for whom prescribing may be considered are needed to derive a better understanding of these drugs and enhance safe and optimal prescribing. Given few existing case reports or clinical trials available on CBD's interactions with other drugs, future research should address and characterize the mechanisms of these interactions. The growing popularity of CBD use and the lack of sufficient information on CBD drug-drug interactions make it imperative that we investigate the impact of CBD upon concomitant drug use in future randomized, controlled trials.

Acknowledgments: The authors thank Dr. Larry A. Walker, Emeritus Director, National Center for Natural Products Research, School of Pharmacy, University of Mississippi, for reviewing the manuscript and providing insightful suggestions.

Corresponding Author: Kevin P. Hill, MD, MHS; Division of Addiction Psychiatry, Beth Israel Deaconess Medical Center, Boston, MA, USA (e-mail: Khill1@bidmc.harvard.edu).

\section{REFERENCES}

1. ElSohly MA, Slade D. Chemical constituents of marijuana: the complex mixture of natural cannabinoids. Life Sci 2005;78(5):539-548.

2. Joy JE, Watson S, Benson J. Marijuana and Medicine. Assessing the Science Base. 1999: 1999.

3. Mikulic M. Global Pharmaceutical Industry-Statistics \& Facts. In: Statista; 2019.

4. Devinsky O, Cilio MR, Cross H, et al. Cannabidiol: pharmacology and potential therapeutic role in epilepsy and other neuropsychiatric disorders. Epilepsia. 2014;55(6):791-802.

5. Pisanti S, Malfitano AM, Ciaglia E, et al. Cannabidiol: state of the art and new challenges for therapeutic applications. Pharmacol Ther 2017; 175:133-150.

6. Campos AC, Fogaça MV, Sonego AB, Guimarães FS. Cannabidiol, neuroprotection and neuropsychiatric disorders. Pharmacol Res 2016;112:119-127.

7. Consroe P, Benedito MA, Leite JR, Carlini EA, Mechoulam R. Effects of cannabidiol on behavioral seizures caused by convulsant drugs or current in mice. Eur J Pharmacol 1982;83(3-4):293-298.

8. Coimbra N, Mendes-Gomes J, Da Silva J, Dos Anjos-Garcia T, Ullah F, Almada R. New Ethological and Morphological Perspectives for the Investigation of Panicolytic-Like Effects of Cannabidiol. In: Handbook of Cannabis and Related Pathologies. Elsevier; 2017:e140-e149.

9. Schiavon AP, Bonato JM, Milani H, Guimarães FS, de Oliveira RMW. Influence of single and repeated cannabidiol administration on emotional behavior and markers of cell proliferation and neurogenesis in nonstressed mice. Prog Neuro-Psychopharmacol Biol Psychiatry 2016;64:2734.

10. Jiang R, Yamaori S, Takeda S, Yamamoto I, Watanabe K. Identification of cytochrome P450 enzymes responsible for metabolism of cannabidiol by human liver microsomes. Life Sci 2011;89(5-6):165-170.

11. Jiang $\mathbf{R}$, Yamaori $\mathbf{S}$, Okamoto $\mathbf{Y}$, Yamamoto $\mathbf{I}$, Watanabe $\mathbf{K}$. Cannabidiol is a potent inhibitor of the catalytic activity of cytochrome P450 2C19. Drug Metabolism and Pharmacokinetics. 2013:DMPK-12-RG129.

12. Zendulka O, Dovrtelová G, Nosková $\mathbf{K}$, et al. Cannabinoids and cytochrome P450 interactions. Curr Drug Metab 2016;17(3):206-226.

13. Bland TM, Haining RL, Tracy TS, Callery PS. CYP2C-catalyzed delta (9)-tetrahydrocannabinol metabolism: kinetics, pharmacogenetics and interaction with phenytoin. Biochem Pharmacol 2005;70(7): 1096-1103.

14. Geffrey AL, Pollack SF, Bruno PL, Thiele EA. Drug-drug interaction between clobazam and cannabidiol in children with refractory epilepsy. Epilepsia. 2015;56(8):1246-1251. 
15. Machado Bergamaschi M, Helena Costa Queiroz R, Waldo Zuardi A, Crippa AS. Safety and side effects of cannabidiol, a Cannabis sativa constituent. Curr Drug Saf 2011;6(4):237-249.

16. Monographie N. Cannabidiol. Deutscher Arzneimittel-Codex (DAC) inkl Neues Rezeptur-Formularium (NRF) DAC/NRF October. 2015;22.

17. Wedman-St Louis B. 14 Drug Interactions \& Dosing Issues. Cannabis as Medicine. 2019.

18. Lauckner JE, Jensen JB, Chen H-Y, Lu H-C, Hille B, Mackie K. GPR55 is a cannabinoid receptor that increases intracellular calcium and inhibits M current. Proc Natl Acad Sci 2008;105(7):2699-2704.

19. Sylantyev S, Jensen TP, Ross RA, Rusakov DA. Cannabinoid-and lysophosphatidylinositol-sensitive receptor GPR55 boosts neurotransmitter release at central synapses. Proc Natl Acad Sci 2013;110(13):51935198

20. Kaplan JS, Stella N, Catterall WA, Westenbroek RE. Cannabidiol attenuates seizures and social deficits in a mouse model of Dravet syndrome. Proc Natl Acad Sci 2017;114(42):11229-11234.

21. Feinshtein V, Erez O, Ben-Zvi Z, et al. Cannabidiol changes P-gp and BCRP expression in trophoblast cell lines. PeerJ. 2013;1:e153.

22. Database MC. https://reference.medscape.com/drug-interactionchecker Accessed March 282020

23. Zou S, Kumar U. Cannabinoid receptors and the endocannabinoid system: signaling and function in the central nervous system. Int $J \mathrm{Mol}$ Sci 2018; 19(3):833

24. Iffland $\mathbf{K}$, Grotenhermen $\mathbf{F}$. An update on safety and side effects of cannabidiol: a review of clinical data and relevant animal studies. Cannabis Cannabinoid Res 2017;2(1):139-154.

25. van de Donk T, Niesters M, Kowal MA, Olofsen E, Dahan A, van Velzen M. An experimental randomized study on the analgesic effects of pharmaceutical-grade cannabis in chronic pain patients with fibromyalgia. Pain. 2019; 160(4):860.

26. Khoury JM, Neves MdCLd, Roque MAV, et al. Is there a role for cannabidiol in psychiatry? World J Biol Psychiatry 2019;20(2):101-116.

27. Database DB. https://www.drugbank.ca/drugs/DB09061/ biointeractions\#target-tab Accessed April 152020.

28. Chesher G, Jackson DM. Anticonvulsant effects of cannabinoids in mice: drug interactions within cannabinoids and cannabinoid interactions with phenytoin. Psychopharmacologia. 1974;37(3):255-264.

29. Consroe P, Wolkin A. Cannabidiol-antiepileptic drug comparisons and interactions in experimentally induced seizures in rats. $J$ Pharmacol Exp Ther 1977;201(1):26-32.

30. Benowitz NL, Nguyen TL, Jones RT, Herning RI, Bachman J. Metabolic and psychophysiologic studies of cannabidiol-hexobarbital interaction. Clin Pharmacol Ther 1980;28(1):115-120.

31. Yamaori S, Okamoto $\mathbf{Y}$, Yamamoto I, Watanabe $\mathbf{K}$. Cannabidiol, a major phytocannabinoid, as a potent atypical inhibitor for CYP2D6. Drug Metab Dispos 2011;39(11):2049-2056

32. Naccarato $\mathbf{M}$, Yoong D, Kovacs C, Gough $\mathbf{K}$. Case report a case of a potential drug interaction between clobazam and etravirine-based antiretroviral therapy. Antivir Ther 2012;17:589-592.

33. Giraud C, Tran A, Rey E, Vincent J, Tréluyer J-M, Pons G. In vitro characterization of clobazam metabolism by recombinant cytochrome P450 enzymes: importance of CYP2C19. Drug Metab Dispos 2004;32(11):1279-1286.

34. Walzer M, Bekersky I, Blum RA, Tolbert D. Pharmacokinetic drug interactions between clobazam and drugs metabolized by cytochrome P450 isoenzymes. Pharmacotherapy 2012;32(4):340-353.

35. Morrison G, Crockett J, Blakey G, Sommerville $\mathbf{K}$. A phase 1, openlabel, pharmacokinetic trial to investigate possible drug-drug interactions between clobazam, stiripentol, or valproate and cannabidiol in healthy subjects. Clin Pharmacol Drug Dev 2019;8(8):1009-1031

36. Grotenhermen F, Gebhardt K, Berger M. Cannabidiol. Solothurn, Schweiz: Nachtschatten Verlag 2016:17-63.

37. Gaston TE, Szaflarski JP. Cannabis for the treatment of epilepsy: an update. Curr Neurol Neurosci Rep 2018;18(11):73.

38. Consroe PF, AL Wolkin Anticonvulsant interaction of cannabidiol and ethosuximide in rats. J Pharm Pharmacol 1977;29(8):500-501.

39. Scuderi C, Filippis DD, Iuvone T, Blasio A, Steardo A, Esposito G. Cannabidiol in medicine: a review of its therapeutic potential in CNS disorders. Phytotherapy Res 2009;23(5):597-602.

40. Gaston TE, Bebin EM, Cutter GR, Liu Y, Szaflarski JP, Program UC Interactions between cannabidiol and commonly used antiepileptic drugs. Epilepsia. 2017;58(9): 1586-1592

41. Gaston TE, Bebin EM, Cutter GR, et al. Drug-drug interactions with cannabidiol (CBD) appear to have no effect on treatment response in an open-label Expanded Access Program. Epilepsy Behav 2019;98:201-206.
42. Socała K, Wyska E, Szafarz M, Nieoczym D, Wlaź P. Acute effect of cannabidiol on the activity of various novel antiepileptic drugs in the maximal electroshock-and $6 \mathrm{~Hz}$-induced seizures in mice: Pharmacodynamic and pharmacokinetic studies. Neuropharmacology. 2019;158:107733.

43. Ujváry I, Hanuš L. Human metabolites of cannabidiol: a review on their formation, biological activity, and relevance in therapy. Cannabis Cannabinoid Res 2016;1(1):90-101.

44. Păunescu H, Coman O, Coman L, et al. Cannabinoid system and cyclooxygenases inhibitors. J Med Life 2011;4(1):11.

45. Gasparyan A, Navarrete F, Manzanares J. P. 417 Effects of cannabidiol and sertraline on behavioral and neurochemical alterations induced by a new long-lasting animal model of PTSD. Eur Neuropsychopharmacol. 2019;29:S296.

46. Sales AJ, Crestani CC, Guimarães FS, Joca SR. Antidepressant-like effect induced by Cannabidiol is dependent on brain serotonin levels. Prog Neuro-Psychopharmacol Biol Psychiatry 2018;86:255-261.

47. Wilson-Morkeh H, Al-Abdulla A, Sien L, Mohamed H, Youngstein T. Important drug interactions exist between cannabidiol oil and commonly prescribed drugs in rheumatology practice. Rheumatology. 2020.

48. Neelakantan H, Tallarida RJ, Reichenbach ZW, Tuma RF, Ward SJ, Walker EA. Distinct interactions of cannabidiol and morphine in three nociceptive behavioral models in mice. Behav Pharmacol 2015;26(3):304314.

49. Gian Y, Gilliland TK, Markowitz JS. The influence of carboxylesterase 1 polymorphism and cannabidiol on the hepatic metabolism of heroin. Chem Biol Interact 2020;316:108914.

50. Manini AF, Yiannoulos G, Bergamaschi MM, et al. Safety and pharmacokinetics of oral cannabidiol when administered concomitantly with intravenous fentanyl in humans. J Addict Med 2015;9(3):204.

51. ElSohly MA, Radwan MM, Gul W, Chandra S, Galal A. Phytochemistry of Cannabis sativa L. In: Phytocannabinoids. Springer; 2017:1-36.

52. Zuardi AW, Shirakawa I, Finkelfarb E, Karniol I. Action of cannabidiol on the anxiety and other effects produced by $\Delta$ 9-THC in normal subjects. Psychopharmacology. 1982;76(3):245-250.

53. Boggs DL, Nguyen JD, Morgenson D, Taffe MA, Ranganathan M Clinical and preclinical evidence for functional interactions of cannabidiol and $\Delta$ 9-tetrahydrocannabinol. Neuropsychopharmacology. 2018;43(1):142-154.

54. Bhattacharyya S, Morrison PD, Fusar-Poli P, et al. Opposite effects of $\Delta$-9-tetrahydrocannabinol and cannabidiol on human brain function and psychopathology. Neuropsychopharmacology. 2010;35(3):764-774.

55. King KM, Myers AM, Soroka-Monzo AJ, et al. Single and combined effects of $\Delta 9$-tetrahydrocannabinol and cannabidiol in a mouse model of chemotherapy-induced neuropathic pain. $\mathrm{Br} J$ Pharmacol 2017;174(17):2832-2841.

56. Todd S, Arnold J. Neural correlates of interactions between cannabidiol and $\Delta$ 9-tetrahydrocannabinol in mice: implications for medical cannabis. Br J Pharmacol 2016;173(1):53-65.

57. Morgan CJ, Freeman TP, Schafer GL, Curran HV. Cannabidiol attenuates the appetitive effects of $\Delta$ 9-tetrahydrocannabinol in humans smoking their chosen cannabis. Neuropsychopharmacology. 2010;35(9): 1879-1885.

58. Todd SM, Zhou C, Clarke DJ, Chohan TW, Bahceci D, Arnold JC. Interactions between cannabidiol and $\Delta 9$-THC following acute and repeated dosing: Rebound hyperactivity, sensorimotor gating and epigenetic and neuroadaptive changes in the mesolimbic pathway. Eur Neuropsychopharmacol 2017;27(2): 132-145.

59. Lucas CJ, Galettis P, Schneider $\mathbf{J}$. The pharmacokinetics and the pharmacodynamics of cannabinoids. $\mathrm{Br} \mathrm{J}$ Clin Pharmacol 2018;84(11):2477-2482.

60. Damkier P, Lassen D, Christensen MMH, Madsen KG, Hellfritzsch M, Pottegård A. Interaction between warfarin and cannabis. Basic Clin Pharmacol Toxicol 2019;124(1):28-31.

61. Leino AD, Emoto C, Fukuda T, Privitera M, Vinks AA, Alloway RR Evidence of a clinically significant drug-drug interaction between cannabidiol and tacrolimus. Am J Transplant 2019; 19(10):2944-2948.

62. Brown JD, Winterstein AG. Potential adverse drug events and drugdrug interactions with medical and consumer Cannabidiol (CBD) use. $J$ Clin Med 2019;8(7):989.

63. Ewing LE, McGill MR, Yee EU, et al. Paradoxical Patterns of Sinusoidal Obstruction Syndrome-Like Liver Injury in Aged Female CD-1 Mice Triggered by Cannabidiol-Rich Cannabis Extract and Acetaminophen Co-Administration. Molecules. 2019;24(12):2256.

64. dos-Santos-Pereira M, da-Silva CA, Guimaraes FS, Del-Bel E. Coadministration of cannabidiol and capsazepine reduces L-DOPA-induced 
dyskinesia in mice: possible mechanism of action. Neurobiol Dis 2016;94:179-195.

65. Nebert DW, Wikvall K, Miller WL. Human cytochromes P450 in health and disease. Philos Transact R Soc B: Biol Sci 2013;368(1612):20120431.

66. Yamaori S, Ebisawa J, Okushima Y, Yamamoto I, Watanabe K. Potent inhibition of human cytochrome P450 3A isoforms by cannabidiol: role of phenolic hydroxyl groups in the resorcinol moiety. Life Sci 2011;88(1516):730-736.

67. Nona CN, Hendershot CS, Le Foll B. Effects of cannabidiol on alcoholrelated outcomes: A review of preclinical and human research. Exp Clin Psychopharmacol 2019;27(4):359.

68. Yang L, Rozenfeld R, Wu D, Devi LA, Zhang Z, Cederbaum A Cannabidiol protects liver from binge alcohol-induced steatosis by mechanisms including inhibition of oxidative stress and increase in autophagy. Free Radic Biol Med 2014;68:260-267.
69. Hamelink C, Hampson A, Wink DA, Eiden LE, Eskay RL. Comparison of cannabidiol, antioxidants, and diuretics in reversing binge ethanolinduced neurotoxicity. J Pharmacol Exp Ther 2005;314(2):780-788.

70. Robinson TE, Berridge KC. The neural basis of drug craving: an incentive-sensitization theory of addiction. Brain Res Rev 1993; 18(3):247-291.

71. Consroe P, Carlini EA, Zwicker AP, Lacerda LA. Interaction of cannabidiol and alcohol in humans. Psychopharmacology. 1979;66(1):45-50.

Publisher's Note: Springer Nature remains neutral with regard to jurisdictional claims in published maps and institutional affiliations. 